\title{
JF 日语教育标准对高校日语教师的要求
}

\author{
李美花 金艺兰
}

延边大学外国语学院

DOI:10.32629/er.v2i11.2162

[摘要] JF日语教育标准是2010年日本国际交流基金制定的一套标准,为全球日语的国际化指明了方向及基准。在高校实施这一标准,要讲好一 堂好课,首先要改变教师的思维模式以及大量的时间及精力的投入。没有教师的付出就不可能有一堂好课。该论文拟从素质、观念、课堂三个 方面对高校日语教师提出了要求。

[关键词] JF日语教育标准; 高校教师; 教学改革

当前, 我国正在全面推进世界一流大学和一流学科建设。2015年10月, 我国颁布实施了 “双一流” 建设的总体方案。我国高校而言, 要实现建设 世界一流大学的奋斗目标, 关键在人, 关键在人才。2018年, 教育部印发《关 于狠抓新时代全国高等学校本科教育工作会议精神落实的通知》, 要求各 高校全面梳理各门课程的教学内容, 淘汰“水课”, 打造“金课”。教高【2019】 6 号文件, 教育部印发了《关于深化本科教育教学改革全面提高人才培养质 量的意见》, 并指出, 要坚持立德树人, 让学生忙起来、教师强起来、管理 严起来、效果实起来。

JF日语教育标准是 2010 年日本国际交流基金制定了一套《JF日语教育 标准2010》纲领性文件。以日语的国际化为目标, 为了更广泛地在海外普 及日语教育, 在 “用日语促进彼此理解” 这一理念的指导下而开发的。是 一套日语教育、学习、评估的参考标准。JF日语教育标准主要包括以下内 容：（1）JF日语教育标准的can-do级别。JF日语教育标准以完成任务的能 力作为分级的指标, 即 “用日语能够做些什么”, 而不是掌握多少单词或知 道多少语法。(2) JF日语教育标准之树。对语言能力构成要素及语言活动 能力的分类及界定。(3) 学习档案袋的建立。记录和保存学习过程, 对学习 成果的评价方式。通过使用JF日语教育标准, 我们可以得知日语使用的熟 练程度。另外, JF日语教育标准也可用于课程设置、教材开发、学生评价 以及设计考试等方面。

JF日语教育标准下, 导入 “can-do” 模式, 以此改变传统的日语教学, 重视学生的输入及输出, 以 “can-do” 作为评价体系, 导入 “学习档案” 强 调学生的自我评价的必要性。在打造 “金课” 的新形式下, 导入 “can-do” 模式, 提高日语课堂的教学质量, 提高学生的日语水平。在高校课堂中, 如 何最大限度地发掘学生的能力, 如何提高学生的解决问题的能力及创新能 力, 这一系列的问题对高校日语教师提出了新的要求。在导入新理念, 新模 式的过程中发现, 一门好课, 需要一个学校、一个学科、一个专业的教师团 队的共同努力及改变, 而不是通过几天, 几个月的努力而形成的。也并非不 是一个老师的改变而改变的。需要创建一支符合时代的, 积极向上的、充 满活力及激情的教师队伍。JF日语教育标准下的 “can-do” 模式的导入, 需要一支全新的队伍, 同时对高校日语教师提出了几点要求。

\section{1 对高校日语教师的素质要求}

1. 1教师要热爱自己的职业

《关于深化本科教育教学改革全面提高人才培养质量的意见》指出, 高校教师的第一身份是老师、第一工作是教书、第一责任是上课, 要引导 老师努力做到政治过硬、业务精湛、育人高超、技术涃熟、主动承载传播 知识、传播思想、传播真理、塑造灵魂、塑造生命、塑造新人的时代重任。 教师职业承担着为人类、国家、社会、行业和家庭的未来培养人才的崇高 使命。教师的世界观、人生观和价值观, 将对学生产生直接和潜移默化的
重要影响, 高校教师更是如此。因此, 对教师而言, 应该要立其身、践其言、 正其行。教师本着 “为人师表、教书育人” 的原则, 全身心地投入到教学 活动中去, 要热爱自己的职业, 要具备崇高的职业精神。

\section{2 教师要有极强的责任心}

在大学里, 教师就是学生的长辈, 就是师长、学长。教师要以宽容的心 去包容学生的瑕疪及缺点, 要以长辈的心态去引领学生的成长。大学生成 长过程中, 世界观、人生观和价值观尚未完全成型。幼稚、毛糙, 教师作为 学长、师长和长者有责任去引导、指导、教导学生, 宽容和纠正学生的过 失。要对学生负责, 要对学生的学业负责。有了责任心, 才对学生负责, 才 对课堂负责。利用好线上线下的课程, 特别是线下的讨论及作业的点评。 认真观察学生的准备情况、倾听情况、互动情况、自主情况与目标达成情 况。要注重过程的评价, 要尊重学生的付出及努力的过程。什么样的评价 体系, 才能正确地学生的学习情况及学习效果, 这与教师的责任心是分不 开的。

1.3 教师要热爱课堂及学生

随着大学功能逐渐转变, 课堂教学在大学教育中的地位和作用也越来 越受到学生、教师、学校、政府和社会的重视。自主创新、构建和谐社会 和素质教育为课堂教学提出了更高的要求和目标。对大学而言, 课堂教学 的好坏不仅影响着学生的进步与发展, 也深刻影响学校和教师的可持续发 展。教师要热爱自己的职业的同时要热爱课堂, 热爱学生。苏联教育家苏 霍姆林斯基认为, 没有爱就没有教育。课堂教学作为教育教学的重要组成 部分, 爱在其中的作用和地位是不言而喻的。热爱课堂、热爱学生, 才能不 断去思考, 去努力如何讲好一门课。热爱课堂、热爱学生, 才能不断提升自 我, 致力于教学研究, 不断摸索适合于当今学生的学习方法。

\section{2 对高校日语教师的观念要求}

2. 1 积极改变观念

当前高校教师大多是在应试教育背景下成长起来的, 还习惯于把知识 点讲得清清楚楚, 习惯于从题库中选择标准答案的题目考察学生。大部分 教师基于多年的教学经验, 安逸于现状。这样培养出来的学生, 其想象力、 独立思考能力不会强。随着学生的质的变化, 随着时代的变化, 要不断更新 教学理念, 教学方式。高校日语教师要积极改变教学理念, 以学生为中心, 要注重学生会什么, 而不是只看重自己讲了什么。要从教师讲, 改变到学生 会, 这样才能把目光更多地投向学习者的需求及目标。传统的学习方式是 一种被动接受的学习方式, 教学改革要把提高学生的主动学习能力作为第 一问题来解决, 努力营造让学生在学习活动中具有支配和控制的权利与能 力。合理确定学习目标, 主动规划学习进程, 科学制定学习策略。让培养学 生的不断增强自我学习、自我发展的内在动力。

2. 2 深入了解教学对象 
了解课堂, 要了解学生。准备一堂课时, 分析教材之前, 要分析学生。 在分析学生的基础上, 才能有效地、合理的安排教学。教学设计当然要基 于教学大纲, 但是脱离学生的教学设计是不合理的。刚升入大学一年级的 学生, 通过自学, 通过动漫、日剧等媒体, 已经对日本有了一定的了解, 甚至 有些学生不再是零起点, 具备一定的听说能力。不了解学生的现状及需求、 目标的情况下, 设计教学设计及评价体系, 是不合理的, 不能称得上是有效 的。在课堂中有效利用基于合作、问题、实践、探究、个性、对话、网络 学习的学习方式, 培养学生的发现问题的能力、课题解决能力、沟通能力、 团结合作能力等综合能力。让学生真正成为学习的主人、课堂的主人。

\section{3 投入时间及精力}

学习新理念, 学习新知识要投入时间及精力。要准备一堂好课, 需要花 费大量的时间去做课前准备, 如课件的设计, 收集相关资料, 学习日本动态, 学习最前沿的知识。JF日语教育标准里设计My “can-do” 评价体系, 需要 花费大量的时间及精力, 没有教师的付出, 就没有学生的进步及发展。课堂 中的提问、交流、辩论和质疑、都要提前精心策划、考虑、并布置。当然 学生也要改变以往的学习方式, 要积极主动去查阅大量参考书籍, 了解并 掌握学科前沿论文。

\section{3 对高校日语教师的课堂要求}

判断一堂课是不是高校课堂, 是不是一堂好课, 应有具体的标准。事实 上, 因学科、因专业、因学者, 其标准有所不同。但是应具有几大标准。一 是, 教学目标是不是落实了那么, 如何讲好一门课呢, 我认为一门好课需要 做好三方面的工作：课前准备、课堂活动、课后的总结及反思。

3. 1 课前准备。首先收集并查阅与课程相关的相关知识。在教学设计 之前要构思本门课程的教学思想、教学体系、教学内容、教学方法和课程 的学时分配与总体安排。设定教学目标时要站在学生的角度去思考问题, 在了解重点与难点的基础上制作课程教案、课件PPT和相关教具。90分钟 的教案, 要有具体的设计及实施方案。多种教学方法的合理安排, 要努力把 难理解的内容, 讲得通俗易懂。

3.2课堂活动。课堂活动要丰富、生动。90分钟的课堂要以饱满的热 情去传授知识, 与学生沟通, 交路。出了热情之外, 还需要抑扬顿挫的声音,
声情并茂的肢体语言。要对讲授内容非常熟练的基础上,利用多媒体与板 书, 智慧课堂等现代化技术手段, 让课堂充满活力。不要一味地填鸭式地讲 授, 要让学生主动去思考问题, 主动参与到课堂中来, 真正实现学生是主人 的角色。

3. 3课后总结及反思。课后要及时总结并反思课堂。总结好的部分及 不好的部分。具体分析, 学生是否掌握了重点及难点, 学生是否学会了该课 文的主要句型的应用等。反思是否语言不当, 反思小组活动中是否存在安 排不合理的问题等。课后的总结和反思不仅仅是针对上课时教师与学生的 行动与互动, 更应该索源备课阶段的点点滴滴。自我评价是完美教学必须 的, 对教学的不断反思可导向自我知识的丰富。

以上, 通过对教师的素质要求, 对教师的观念要求, 对教师的课堂要求 等三个方面, 对教师提出了要求。作为教师, 就应该坚持把上好每节课、讲 好每堂课作为自己的第一要务, 而不是去简单应付, 就应该把教学作为一 项事业去热爱、去珍惜。一堂好课, 需要教师的付出, 需要老师的精心经营。 只要教师了解学生, 了解学生的需求, 站在学生的角度去思考问题, 这样的 课堂, 这样的教师相信定会受到学生的欢迎的。也可以真正称之为“好课”。

\section{[参考文献]}

[1]枈一鸣.高校教师如何上好一门课[J].中国大学教学,2014,(9):22-26.

[2]许长明,殷娟.JF日语教育标准与学生评价体系 [J]. 教育现代 化,2018,5(48):141-142.

[3]吴岩.建设中国“金课” [J].中国大学教学,2018,(12):4-9.

\section{作者简介:}

李美花(1975--), 女, 朝鲜族, 黑龙江省五常市, 延边大学外国语学 院副教授、硕士、研究方向: 日语教育、日本文化。

金艺兰(1974--),女,朝鲜族,吉林省珲春市,延边大学外国语学院 讲师,硕士; 研究方向：日语教育。

课题来源:

吉林省本科高等教育教学改革立项课题 2017,延边大学人文社会 科学基金项目,项目编号 ND2017005。 